\title{
Endodontic Management of Dilaceratd Roots: A Case Series
}

\author{
Abhishek Gupta ${ }^{1}$, Pooja Kabra ${ }^{2}$ \\ ${ }^{1}$ MDS $3^{\text {rd }}$ Year Post Graduate Student in the Department of Conservative Dentistry and Endodontics, School of Dental Sciences, Sharda \\ University,Greater Noida, India \\ ${ }^{2}$ Reader \& MDS Department of Conservative, \\ Dentistry and Endodontics, School of Dental Sciences, Sharda University, Greater Noida, India
}

\begin{abstract}
Root dilaceration is defined as a deformity that is characterized by displacement of a tooth's root from its normal alignment with the crown. Controlled regularly tapered preparation of the curved canals is the ultimate challenge in endodontics. This article gives a review of the literature and two interesting case reports of root dilacerations.
\end{abstract}

Keywords: root dilaceration, flexible file, precurved files, crown down technique, protaper

\section{Introduction}

The term 'dilaceration' refers to an angulation or a sharp bend or curve, in the root or crown of a formed tooth (Latin: dilacero $=$ tear up) $[1]$.

It was first used by Tomes in 1848[2]and refers to an angulation that may occur anywhere along the length of the tooth, that is, its crown along the root, or by only involving the apex of the root.

\section{Etiology}

The exact etiology of dilacerations is still controversial but the most accepted cause is mechanical trauma to the primary predecessor tooth [3]. However, this pathogenesis has been questioned. The other possible contributing factors that have been proposed include the ectopic development of the tooth germ, presence of scar/ infection/ cyst/ tumour, developmental anomaly of tooth germ, lack of space, syndrome and hereditary factors[4].

The prevalence of dilacerations ranges from $0.32 \%$ to $7 \%$ but only $0.45 \%$ in mandibular first molar. Mandibular third molars are affected most often, while the maxillary arch is affected more than the mandibular arch.

\section{Diagnosis of Dilaceration}

Although dilacerations of a crown can be observed visually in the oral cavity, radiographic examination is required to diagnose a dilacerated root. The direction of root dilacerations can be in single plane or two planes. If the root bends mesially or distally, the dilacerations can be clearly apparent on a periapical radiograph while in buccal / palatal (lingual) direction it gives 'bull's eye' appearance.

When the root dilaceration is in labial direction, it is called a 'scorpion tooth'. If a tooth is doubly affected, it is called a bayonet dilaceration. According to severity; dilaceration can be mild, moderate, or severe.

\section{Methods to Determine the Curvature}

First and the most common method- Schneider in 1971Degree of canal curvature was defined as the acute angle between the long axis of the canal and a line from the point of initial curvature to the apical foramen.

In 1982, Weine proposed another method in which the acute angle between the lines passing through the apical and coronal portions was measured.

Pruett et al (1997) pointed out that the shape of any root canal curvature could be more accurately described using two parameters a) Angle of curvature b) Radius of curvature.

\section{Various Techniques Used for Management}

1)Good preoperative and working radiographs,

2)Unobstructed access to the root canal orifice, as direct access as possible to the apical third of the canal

3) Precurvature of all files used (the sharper the canal curvature, the nearer the bend of the file should be to its tip)

4)Use of intermediate size of files

5)Use of flexible files

6) Anti-curvature filing.

7)Use of crown-down sequence of instrumentation

8)Thorough irrigation

9)Use of warm or thermoplasticized gutta-percha obturation technique

\section{Case Reports}

Case 1

A 35-year-old female reported in department of conservative and endodontics,Sharda University,Greater Noida,U.P,India with pain in relation to right mandibular first molar.

Radiograph revealed the carious pulp exposure with widening of the periodontal ligament space, It also revealed unusual root morphology of the distal root which showed a 


\section{International Journal of Science and Research (IJSR) \\ ISSN (Online): 2319-7064 \\ Index Copernicus Value (2013): 6.14 | Impact Factor (2014): 5.611}

sharp curvature at apical third.

The tooth was anaesthetized with lignocaine $2 \%$ with epinephrine 1:100 000 and a conventional endodontic access opening was made using round carbide bur (ISO 014) and Endo-Z FG burs (Cavity Access Z Set, Dentsply Maillefer, Ballaigues, Switzerland) under rubber-dam isolation..Clinical exploration of canal orifices were made with a DG-16 endodontic explorer (Hu-Friedy, Chicago, IL, USA) . A 10 \# $\mathrm{K}$ file (Mani Inc.) was precurved in accordance with the degree of curvature seen in radiograph. This 10 \# K file glide path was ascertained till radiographic working length. Estimated length till the curvature was marked on the enginedriven instrument and then the coronal flaring was done with gates gridden drill no. 1-4 (Mani Inc.). Working length was then confirmed using apex locator (Propex II) in all canals. The canal was thoroughly debrided with copious irrigation of and $17 \%$ ethylene diamine tetra acetic acid (EDTA) followed by sodium hypochlorite(2.5\%).Now, with rotary Protaper (Dentsply/Maillefer, Ballaigues, Switzerland)cleaning and shaping was achieved (at 300rpm) in all canals in a crown down manner.S1 was used in brushing motion till the working length. Shaping of the canal was then done by S1 and S2 till the working length, with periodic recapitulation of \# $10 \mathrm{~K}$ flex file (Dentsply Maillefer, Ballaigues, Switzerland). Distalroots, canals was finished till F1. In mesial roots, cleaning and shaping was done till F2. After finishing, master cone was selected and obturation was done using carrier based system alongwith AH Plus sealer. The access cavity was restored with glass ionomer cement (Filtek Z250, 3m ESPE,USA), and a postoperative radiograph was taken.

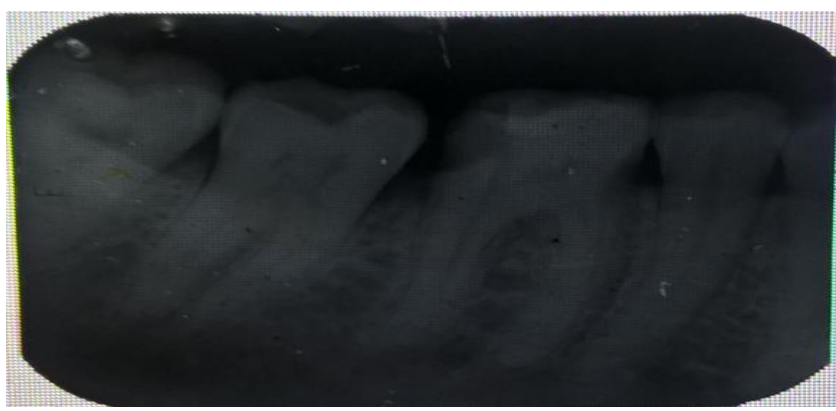

Figure 1: Pre operative IOPAR of tooth 46

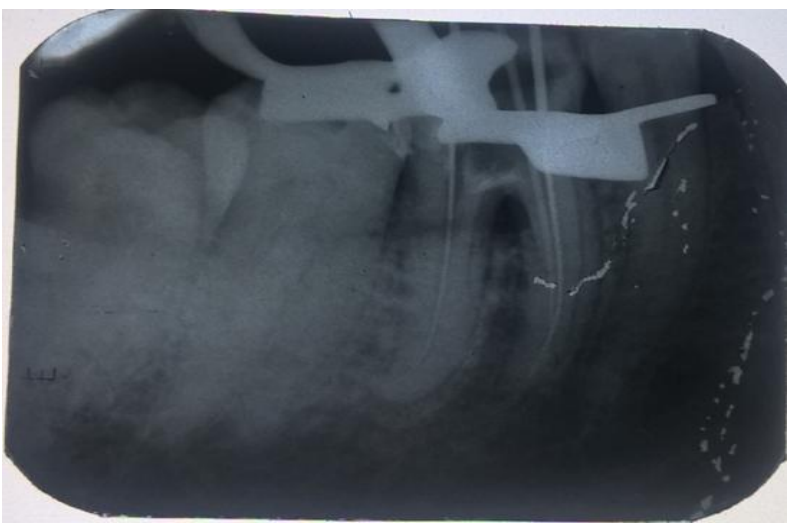

Figure 2: Working length IOPAR wrt 46

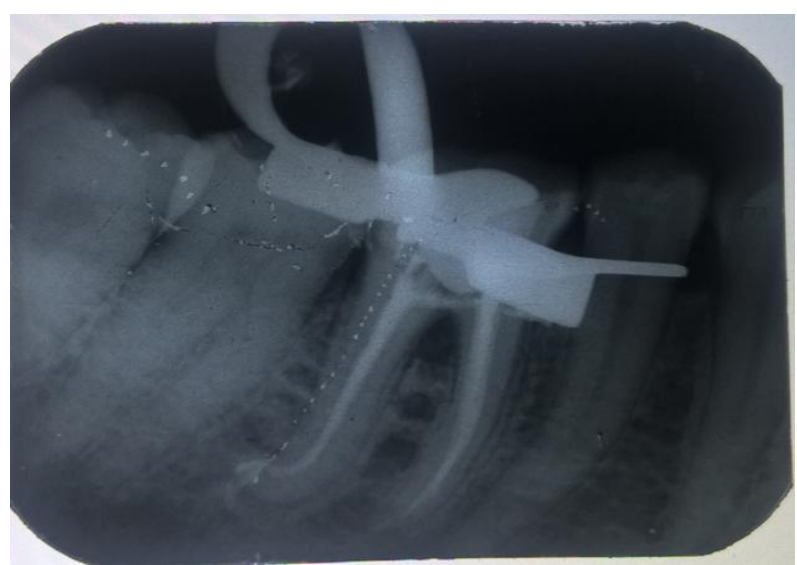

Figure 3: Obturation with carrier based system wrt 46

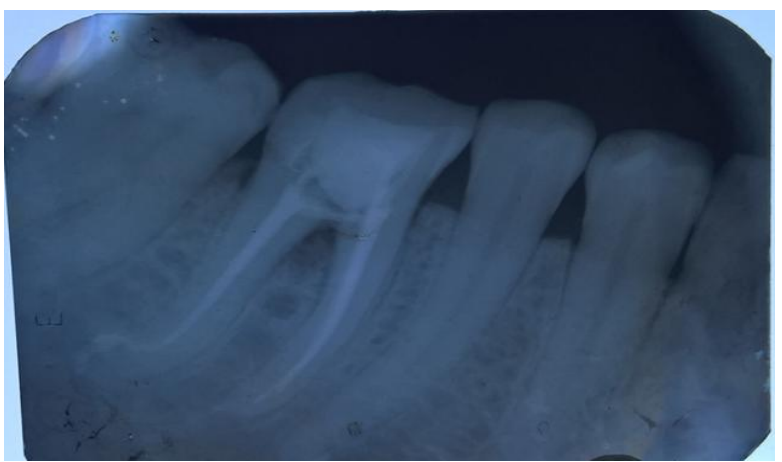

Figure 4: Post- obturation IOPAR wrt 46

\section{Case 2}

A 24 year old male reported in our department with pain in in the lower left back tooth. Radiograph revealed widening of the periodontal ligament space.It also showed root morphology of the mesial root which showed a slight curvature .Treatment steps were same as for case 1.

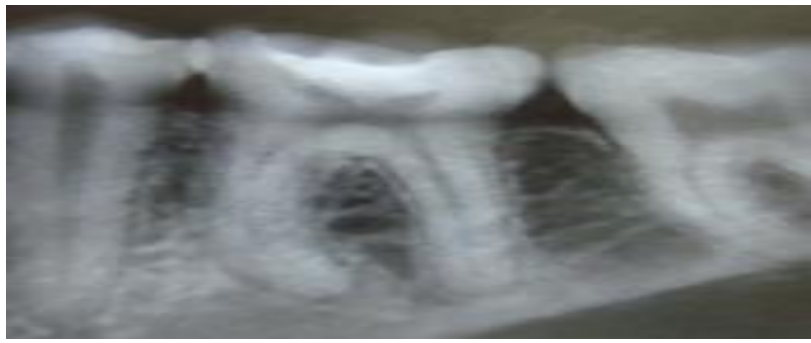

Figure 5: Pre operative IOPAR of tooth 36

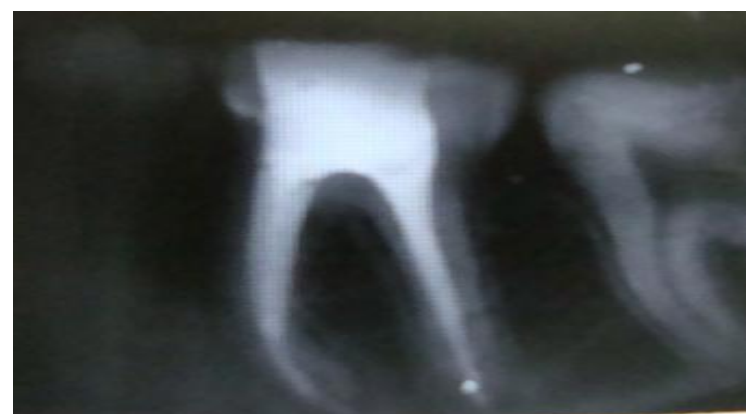

Figure 6: Post- obturation IOPAR wrt 36

\section{Discussion}

The presence of curvatures and canal dilacerations can present a tremendous challenge and complicate endodontic

\section{Volume 5 Issue 3, March 2016}




\section{International Journal of Science and Research (IJSR) \\ ISSN (Online): 2319-7064}

Index Copernicus Value (2013): 6.14 | Impact Factor (2014): 5.611

treatment. Error in maintaining root canal curvature can result in ledge formation, apical transportation, zipping, perforation, and instrument breakage [5].

Preenlarging or reverse flaring and crown-down preparations has shown to improve tactile control when directing smaller, precurved negotiating files so as to promote removal of dentinal debris, thus enhancing the cleaning of the canal[6].In the present cases gates glidden drill was used for flaring.

In dilacerated teeth it is often difficult to explore and negotiate the canal to its apical foramen; hence the use of scout file is recommended in these kind of cases [7]. In the present cases \# 10k file was inserted in watch-winding motion to confirm the canal patency. Also precurving of all instruments was done to allow the files to follow the curve and not just cut in a straight direction.

Root dilaceration is diagnosed via radiographic examination[4].Rohlin et al. [8] reported that better results could be obtained with periapical radiography than panoramic radiography, in terms of identification of lesions at the periapex. In the present cases also periapical radiograph was used for dilacerations diagnosis.

During the root filling phase of treatment, the smear layer prevents close contact of the filling material with the root canal walls, acting as an interface and facilitating microleakage .A currently used protocol for the removal of the smear layer is a combined rinse with ethylenediaminetetraacetic acid (EDTA) and sodium hypochlorite $(\mathrm{NaOCl})$ [9] which was used in present case series.

In the present case series carrier based obturation was used.Although lateral compaction of curved canals can be very effective in most teeth, this technique might be difficult and sometimes impossible in dilacerated canals. If the lateral compaction technique is chosen, then spreaders made from NiTi are highly recommended for the filling of severely curved root canal systems. The use of warm or thermoplasticized gutta-percha techniques might be more applicable in these cases[4].Also AH Plus was used in present case series as sealer. Rouhani et. $\mathrm{Al}[10]$ reported that Resilon/Epiphany provided a better seal than guttapercha/AH-Plus in severely curved root canals immediately after obturation, although with the passage of time, Resilon/Epiphany was equivalent to gutta-percha/AH Plus in sealing properties.

Owing to their specific design and flexibility, NiTi rotary files make root canal preparation safer and more efficient because they provide better centering in the canal when compared with stainless-steel hand files even in severely curved root canals[11].Shaping of root canal was done by ProTaper Universal system.A new design feature of ProTaper Universal system comprises the more rounded tips of the finishing files with the aim to increase the working safety as well as to improve shaping ability. Furthermore, the cross-section design has been modified to increase its inherent flexibility, cutting and efficiency with low proportion of apical deviation as demonstrated in the present investigation and in previous studies [12]. These findings are in contrast to a previous study [13] in which the ProTaper Universal showed a greater tendency to produce apical transportation. Also some novel NiTi rotary instruments are currently being marked to maintain root canal anatomy. Saber et al.[14] reported that ProTaperNext, iRaCe and Hyflex CM rotary NiTi files respected original canal curvature well and were safe to use.

\section{Conclusion}

The presence of a dilaceration must be identified before treatment, and this can be achieved by a thorough clinical and radiographic examination. Clinicians should be aware of all the basic principles, modification and latest technology of endodontic therapy to manage these kinds of cases.

\section{References}

[1] Shafer WG, Maynard KH, Bernet ML. Oral Pathology. W.B. Saunders Co: Philadelphia; 1993. p. 40.

[2] Tomes J. A course of lectures on dental physiology and surgery.London: Gryphon Editions, Ltd.; 1846.

[3] Matsuoka T, Sobue S, Ooshima T. Crown dilaceration of a first premolar caused by extraction of its deciduous predecessor: a case report. Endod Dent Traumatol. 2000;16(2):91-4.

[4] Jafarzadeh H, Abott PV. Dilaceration: review of an endodontic challenge. J Endod. 2007;33(9):1025-30.

[5] Walton RE, Torabinejad M. Principles and practice of endodontics. 2nd ed. Philadelphia: WB Saunders; 1996.

[6] Barbieri N, Leonardi DP, Baechtold MS, Correr GM, Gabardo MC, Zielak JCet al. Influence of cervical preflaring on apical transportation in curved root canals instrumented by reciprocating file systems.BMC Oral Health.2015 Nov 23;15:149.

[7] Dastmalchi N, Kazemi Z, Hashemi S, Peters OA, Jafarzadeh $H$. Definition and endodontic treatment of dilacerated canals: a survey of Diplomates of the American Board of Endodontics. J Contemp Dent Pract. 2011;12(1):8-13.

[8] Rohlin M, Kullendorff B, Ahlqwist M, Henrikson CO, Hollender L, Stenstro“m B. Comparison between panoramic and periapical radiography in the diagnosis of periapical bone lesions. Dentomaxillofac Radiol. 1989;18:151-5.

[9] Mello I, Kammerer BA, Yoshimoto D, Macedo MC, Antoniazzi JH. Influence of final rinse technique on ability of ethylenediaminetetraacetic acid of removing smear layer. J Endod 2010; 36: 512-14.

[10] Rouhani A, Ghoddusi J, Naghavi N, Ebadzadeh Z, Akbari M. The sealing ability of resilon and gutta-percha in severely curved root canals: an in vitro study.J Dent (Tehran).2013 Mar;10(2):141-6.

[11] Schirrmeister JF, Strohl C, Altenburger MJ, Wrbas KT, Hellwig E. Shaping ability and safety of five different rotary nickel-titanium instruments compared with stainless steel hand instrumentation in simulated curved root canals. Oral Surg Oral Med Oral Pathol Oral Radiol Endod. 2006;101:807-13.

[12] Aguiar CM, Mendes DA, Câmara AC, Figueiredo JAP. 
Evaluation of the centreing ability of the ProTaper Universal TM rotary system in curved roots in comparison to Nitiflex ${ }^{\mathrm{TM}}$ files. Aust Endod J 2009; 35: 174-9.

[13] Kunert GG, Fontanella VRC, de Moura AAM, Barletta FB. Analysis of apical root transportation associated with ProTaper Universal F3 and F4 instruments by using digital subtraction radiography. J Endod 2010; 36: 1052-5.

[14] Saber SE, Nagy MM, Schäfer E. Comparative evaluation of the shaping ability of ProTaper Next, iRaCe and Hyflex CM rotary NiTi files in severely curved root canals. Int Endod J. 2015 Feb;48(2):131-6.

\section{Author Profile}

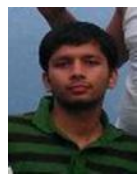

Abhishek Gupta received the B.D.S degree from Baba Jaswant Singh Dental College, Ludhiana, Punjab in 2012 and is currently pursuing his post graduation degree in Conservative and Endodontics Dentistry from Sharda university, Greater Noida, U.P.

Pooja Kabra graduated from a reputed institute KGMC, Lucknow in year 2001 and post graduation in year 2005. In 2007 joined as senior lecturer in Krishna dental college, Ghaziabad \& served for 4 years and was promoted to reader. Thereafter joined a in Sharda University and serving till now. 